\title{
Ekstraksi Pembuluh Darah pada Citra Retina Mata
}

\author{
Blood Vessels Extraction in Retinal Image
}

\author{
Indah Susilawati \\ Program Studi Teknik Informatika, Fakultas Teknologi Informasi, Universitas Mercu Buana \\ Yogyakarta, Jl. Wates Km. 10 Yogyakarta 55753, Indonesia \\ Email: indah_nik@yahoo.co.id
}

\begin{abstract}
ABSTRAK
Deteksi dan ekstraksi pembuluh darah pada retina mata merupakan salah satu langkah penting untuk mengetahui atau mendiagnosa beberapa penyakit yang terkait dengan mata, misalnya mengetahui adanya pertumbuhan pembuluh darah yang tampak pada optic disc pada citra retina mata yang menandai adanya penyakit diabetes militus. Seorang pakar medis biasanya melakukan segmentasi pembuluh darah pada retina secara manual untuk kepentingan tersebut. Cara manual ini dilakukan dengan mendasarkan diri pada citra retina mata yang biasanya dihasilkan menggunakan kamera fundus. Dalam penelitian ini dilakukan ekstraksi pembuluh darah pada citra retina mata berbantuan komputer menggunakan cara-cara pengolahan citra digital. Dengan mengambil citra aras keabuan kanal Y (luminansi) dari citra, pembuluh darah diekstraksi setelah dilakukan peningkatan kontras menggunakan metode CLAHE untuk kemudian dilakukan segmentasi dengan cara thresholding. Penelitian menunjukkan bahwa metode berhasil melakukan ekstraksi pembuluh darah pada retina mata dengan akurasi tertinggi 72,47\%. Hasil juga menunjukkan bahwa secara visual pembuluh darah berhasil diekstrak dengan baik, sebagian besar pembuluh darah yang tidak berhasil diekstrak merupakan pembuluhpembuluh yang sangat halus.
\end{abstract}

Kata kunci: CLAHE; peningkatanan kontras; kamera fundus; citra retina mata; segmentasi; thresholding.

\begin{abstract}
Detection and extraction of blood vessels in the retina of the eye is one of the important steps to identify or diagnose several eye-related diseases, such as knowing the presence of visible blood vessels in optic discs on the retinal image of the eye that indicate the presence of diabetes mellitus. A medical expert usually performs retinal blood vessels segmentation manually for that purpose. This manual way is done based on retinal fundus images. In this study, extraction of blood vessels in retinal images is done using digital image processing methods. Taking the gray-level image of the Y channel (luminance) of the image, the blood vessels are extracted after a contrast enhancement using the CLAHE method and segmented through thresholding. Research shows that the method successfully extract blood vessels in the retina with the highest accuracy of $72.47 \%$. The results also showed that the blood vessels were successfully extracted, leaving only subtle vessels.
\end{abstract}

Keywords: CLAHE; contrast enhancement; fundus camera; retinal image; segmentation; thresholding.

\section{PENDAHULUAN}

Deteksi dan ekstraksi pembuluh darah pada retina mata merupakan salah satu langkah penting untuk mengetahui atau mendiagnosa beberapa penyakit yang terkait dengan mata, misalnya mengetahui adanya pertumbuhan pembuluh darah yang tampak pada optic disc pada citra retina mata yang menandai adanya penyakit diabetes militus. Seorang pakar medis biasanya melakukan segmentasi pembuluh darah pada retina secara manual untuk kepentingan tersebut. Cara manual ini dilakukan dengan mendasarkan diri pada citra retina mata yang biasanya dihasilkan menggunakan kamera fundus.

Segmentasi pembuluh darah pada retina secara manual tentu saja membutuhkan seorang ahli yang berpengalaman untuk meminimalkan kesalahan. Selain itu, segmentasi secara manual ini juga cenderung memakan waktu. Konsekuensi yang sering 
harus ditanggung adalah kinerja atau akurasi yang tidak menentu yang diakibatkan oleh tingkat pengalaman operator ataupun karena faktor kelelahan operator.

Teknik pengolahan citra digital memungkinkan untuk melakukan segmentasi pembuluh darah pada retina menggunakan bantuan komputer. Dengan menerapkan berbagai algoritma untuk prapengolahan dan segmentasi diharapkan dapat dicapai kinerja dan akurasi yang dapat diandalkan untuk melakukan deteksi dan ekstraksi pembuluh darah secara otomatis. Dengan cara ini pula dapat dihindarkan tidak menentunya kinerja dan akurasi karena faktor pengalaman dan tingkat kelelahan.

Pada penelitian ini dilakukan ekstraksi pembuluh darah pada citra retina mata yang diakuisisi menggunakan kamera fundus. Proses ekstraksi ini diharapkan dapat menjadi tahap awal dari proses yang lebih lanjut untuk membantu proses diagnosa suatu penyakit terkait.

\section{TINJAUAN PUSTAKA}

Penelitian sebelumnya yang terkait dengan proses segmentasi adalah penelitian yang dilakukan oleh H. Mirzaalian dkk (2007) dengan judul "Pre-processing Algorithms on Digital Mammograms". Dalam penelitiannya dilakukan ekstraksi kontur payudara dari citra mamografi menggunakan proses ekualisasi histogram, konvolusi dengan mask, pengambangan, labeling, dan seleksi area yang terluas. Selanjutnya dilakukan modifikasi kontur menggunakan proses morfologi sehingga diperoleh kontur yang lebih halus. Algoritma yang dikembangkan diterapkan pada 90 citra mamografi yang diperoleh dari MIAS.

Kumar dkk (2013) dalam penelitiannya berjudul "Automatic Detection of Vasculature from the Images of Human Retina Using CLAHE and Bitplane Decomposition". Dalam penelitian ini dilakukan deteksi dan segmentasi pembuluh darah dari citra retina mata. Pendekatan baru yang digunakan sederhana dengan mengambil kanal hijau dari citra retina. Kontras citra diperbaiki menggunakan CLAHE (Contrast Limited Adaptive Histogram Equalization) dan mathematical morphology. Dekomposisi bitplane pada citra output dan serangkaian operasi morfologi digunakan untuk proses segmentasi akhir. Pada penelitian ini, bitplane ke 2 dipilih karena membawa informasi penting mengenai topologi pembuluh retina mata. Tingkat akurasi yang diperoleh setinggi $92,392 \%$.

Budai dkk (2013) dalam penelitiannya berjudul "Robust Vessel Segmentation in Fundus Images", melakukan segmentasi pembuluh darah pada citra fundus. Penelitian yang dilakukan menggunakan metode yang menghemat waktu perhitungan, mencapai akurasi yang tinggi, dan meningkatkan sensitivitas jika dibandingkan dengan metode Frangi. Akurasi rata-rata yang dicapai pada penelitian ini setinggi $94 \%$.

Penelitian yang lain dilakukan oleh Saleh dkk (2011) dengan judul "An Automated Blood Vessel Segmentation Algorithm Using Histogram Equalization and Automatic Threshold Selection". Dalam penelitian ini dilakukan konversi citra warna ke aras keabuan dan kanal hijau, perbaikan kontras menggunakan CLAHE, proses penghilangan background, dan kemudian dilakukan pengambangan dan post-filtration. Untuk proses pengambangan digunakan teknik isodata untuk menemukan nilai ambang yang tepat secara otomatis. Akurasi yang dicapai setinggi 95,54\% (berdasar citra aras keabuan) dan 96,3\% (berdasar kanal hijau).

Jelinek dkk melakukan penelitian berjudul "Automated Segmentation of Retinal Blood Vessels and Identification of Proliferative Diabetic Retinopathy" pada tahun 2007. Pada penelitian tersebut dilakukan segmentasi secara otomatis menggunakan alihragam wavelet Gabor dan kemudian mengklsifikasikannya menggunakan ciri-ciri yang telah biasa digunakan yaitu area dan perimeter, serta ciri tambahan berupa lima ciri morfologi. Analisis diskriminan mengindikasikan bahwa ciri-ciri area dan perimeter tidak mampu mendeteksi dini retinopathy proliferatif. Analisis diskriminan dengan enam ciri menghasilkan AUC setinggi 0,9. Metode wavelet mampu mensegmentasi pembuluh darah retina dan mengklasifikasikan citra menurut ada atau tidaknya retinopathy proliferatif.

Pavai dan Selvi (2013) melakukan penelitian berjudul "Identification of Proliferative Diabetic Retinopathy Using Texture Segmentation". Dalam penelitian tersebut dilakukan identifikasi retina normal dan abnormal (akibat penyakit diabetes militus). Identifikasi dilakukan menggunakan 
SVM dengan 15 ciri yang mewakili bentuk dan gradien pembuluh darah pada optic disc citra retina mata. Penelitian menghasilkan sensitivitas $88,89 \%$ dan spesifisitas $91,3 \%$.

\subsection{Citra Warna}

Citra warna dapat dinyatakan dengan banyak cara, salah satunya adalah dengan menggunakan model RGB. Pada model ini, sebuah citra berwarna dinyatakan sebagai gabungan dari tiga buah warna monochrome merah, hijau, dan biru. Warna untuk setiap pikselnya tergantung dari komposisi ketiga komponen pada koordinat tersebut. Berbagai analisis berdasarkan warna obyek dapat mempergunakan ketiga lapisan $R, G$, dan $B$ dalam prosesnya.

Citra warna yang dinyatakan dengan model warna $R G B$, pada dasarnya dapat ditampilkan sebagai tiga citra monocrome menggunakan ketiga lapis yang ada yaitu lapisan $R$, lapisan $G$, dan lapisan B. Masingmasing lapisan ini sering juga disebut kanal (channel) sehingga terdapat istilah kanal merah, kanal hijau dan kanal biru.

Model untuk menyatakan citra warna yang lainnya adalah model YIQ yang digunakan untuk standart TV/video di negaranegara yang memakai standart video NTSC. Komponen Y merupakan luminansi (berkaitan dengan intensitas), dan komponen I dan $Q$ membawa informasi warna (kroma). Konversi antara $R G B$ dan YIQ dapat dilakukan menggunakan matriks pada persamaan (1) dan (2) berikut.

$$
\begin{gathered}
{\left[\begin{array}{l}
Y \\
I \\
Q
\end{array}\right]=\left[\begin{array}{ccc}
0,299 & 0,587 & 0.114 \\
0,596 & -0,274 & -0,322 \\
0,211 & -0,523 & 0,312
\end{array}\right]\left[\begin{array}{l}
R \\
G \\
B
\end{array}\right]} \\
{\left[\begin{array}{l}
R \\
G \\
B
\end{array}\right]=\left[\begin{array}{ccc}
1 & 0,956 & 0.621 \\
1 & -0,272 & -0,647 \\
1 & -1,106 & 1,703
\end{array}\right]\left[\begin{array}{l}
Y \\
I \\
Q
\end{array}\right]}
\end{gathered}
$$

Terkait dengan pemrosesan citra warna dan model warna yang digunakan, dapat dilakukan dua cara berikut:

1. Memproses atau mengolah lapisan $R, G$, dan B secara terpisah,

2. Mentrasformasi menjadi color space yang lain yang memisahkan intensitas dari warna, kemudian mengolah komponen intensitasnya saja. Sebagai contoh, perbaikan kontras untuk citra warna paling baik dilakukan dengan mengolah komponen intensitasnya/komponen- $Y$ dari model warna YIQ. Dalam hal ini jika citra pada awalnya dinyatakan dengan model warna $R G B$ maka harus dikonversi terlebih dahulu menjadi model warna YIQ.

\subsection{Histogram Citra}

Histogram citra menyajikan penyebaran nilai-nilai intensitas piksel dari suatu citra atau bagian tertentu di dalam citra. Dari sebuah histogram dapat diketahui frekuensi relatif kemunculan setiap nilai aras keabuan pada citra. Berdasarkan histogram citra, dapat diketahui informasi tentang kontras citra; kontasnya baik atau kurang baik.

Untuk citra warna, histogram dinyatakan untuk setiap komponen RGB citra sehingga untuk setiap citra warna dapat dibuat tiga buah histogram.

Citra yang memiliki kontras buruk dapt diperbaiki dengan cara merentangkan aras keabuannya (histogram stretching) agar lebih merata, misalnya dengan menggunakan fungsi linear sebagian-sebagian (piecewise linear function) seperti Persamaan (3) adalah fungsi yang mempunyai efek merentangkan aras keabuan.

$$
\mathrm{y}=\left(\frac{\mathrm{x}-\mathrm{a}}{\mathrm{b}-\mathrm{a}}\right)(\mathrm{d}-\mathrm{c})+\mathrm{c}
$$

dengan $x$ adalah piksel citra input dan y adalah piksel outputnya. Nilai piksel yang lain dapat dibiarkan saja (tidak diubah).

Cara yang lain adalah ekualisasi histogram yang merupakan prosedur otomatis secara keseluruhan. Histogram citra diubah menjadi histogram yang seragam atau uniform; yaitu bahwa setiap batang pada histogram mempunyai tinggi yang sama, atau dengan kata lain bahwa setiap aras keabuan pada citra memiliki frekuensi kemunculan yang sama. Misalkan sebuah citra mempunyai $L$ aras keabuan yaitu 0, 1, 2, 3, .., L-1 dan setiap aras keabuan $i$ muncul sebanyak $n_{i}$ kali. Jika jumlah piksel dalam citra adalah $n$ (sehingga $n_{0}+n_{1}+n_{2}$ $+\ldots+n_{L-1}=n$ ), maka untuk mentransformasikan aras keabuan citra menjadi citra dengan kontras yang lebih baik, aras keabuan i diubah menjadi sesuai dengan persamaan (4).

$$
\left(\frac{\mathrm{n}_{0}+\mathrm{n}_{1}+\ldots+\mathrm{n}_{\mathrm{i}}}{\mathrm{n}}\right)(\mathrm{L}-1)
$$

dan kemudian dibulatkan ke nilai yang terdekat. 
Untuk citra yang mempunyai bagianbagian yang berkontras rendah, gelap atau terang, ekualisasi histogram yang sifatnya global tidak dapat berpengaruh secara efektif. Salah satu modifikasi ekualisasi histogram disebut Adaptive Histogram Equalization (AHE) dapat digunakan untuk memperoleh hasil yang lebih baik. AHE bekerja dengan memperhatikan hanya sebagian kecil wilayah citra saja dan mendasarkan diri pada Cumulative Density Function (CDF) lokal, yang melakukan perbaikan kontras pada wilayah tersebut. AHE dapat diimplemetasikan dengan berbagai metode dan setiap metode mempunyai banyak variasi.

Saat menerapkan AHE, jika wilayah citra yang sedang diproses mempunyai jangkauan intensitas yang relatif kecil dibandingkan maka derau pada wilayah tersebut menjadi ditingkatkan (enhanced). Hal itu juga menyebabkan semacam cacat (artifact) terlihat pada wilayah tersebut. Untuk meminimalkan hal ini, terdapat satu modifikasi metode AHE yang disebut Contrast Limited Adaptive Histogram Equalization (CLAHE). Besarnya peningkatan konstras untuk beberapa intensitas berbanding lurus dengan kemiringan fungsi CDF pada level intensitas tersebut. Dengan demikian peningkatan kontras dapat dibatasi dengan cara membatasi fungsi CDF pada level intensitas tersebut.

\subsection{Filter Nonlinear}

Filter non linear diperoleh dengan menggunakan fungsi non linear yang dikenakan pada nilai-nilai piksel dalam "mask". Termasuk dalam jenis filter nonlinear adalah filter maksimum (maximum filter) dan filter minimum (minimum filter). Filter maksimum menghasilkan output berupa nilai piksel maksimum dalam mask, dan sebaliknya filter minimum menghasilkan output berupa nilai piksel minimum dalam mask.

Baik filter maksimum maupun filter minimum termasuk dalam golongan rank-order filters. Dalam filter yang demikian, elemenelemen yang berada di dalam "mask" akan diurutkan (ordered) dan satu nilai tertentu dikeluarkan sebagai output. Dengan demikian, jika nilai-nilai tersebut diurut menaik, maka filter minimum adalah rank-order filter dimana elemen pertamanya dikeluarkan sebagai output; sedangkan filter maksimum merupakan rank-order filter dimana elemen terakhirnya yang dikeluarkan sebagai output. Rank-order filter lain yang sangat penting adalah filter median. Pada filter median maka nilai tengah dari nilai-nilai piksel (dalam mask) yang telah diurutkan akan dikeluarkan sebagai output.

\subsection{Segmentasi}

Segmentasi citra digunakan untuk memilih obyek tertentu dalam citra. Salah satu cara segmentasi yang paling sederhana adalah thresholding. Citra aras keabuan dapat diubah menjadi citra biner (hitam putih, black and white, $B W$ ) dengan terlebih dulu memilih suatu nilai threshold $T$ dan kemudian mengubah setiap piksel menjadi hitam atau putih seperti pada persamaan (5).

$$
\mathrm{y}=\left\{\begin{array}{l}
\text { putih jika } \mathrm{x}>\mathrm{T} \\
\text { hitam jika } \mathrm{x} \leq \mathrm{T}
\end{array}\right.
$$

Pada beberapa kasus tidak dimungkinkan untuk memilih satu atau dua nilai ambang yang dapat mengisolasi objek secara keseluruhan. Untuk hal yang seperti ini biasanya digunakan adaptive thresholding. Adaptive thresholding menggunakan nilai ambang yang berbeda-beda bergantung pada lokasi citra atau sering disebut pengolahan lokal (localized). Misalnya dengan menggunakan parameter nilai rerata (mean) atau median dari suatu jendela (window) pada citra yang bersangkutan.

Hasil proses thresholding dapat diperbaiki menggunakan pengolahan morfologi seperti dilasi dan erosi. Pengolahan ini termasuk jenis pengolahan citra yang sangat penting untuk analisis bentuk.

\section{METODOLOGI PENELITIAN}

Langkah-langkah penelitian dilakukan dan dijelaskan dengan urutan sebagai berikut.

a. Citra aras keabuan kanal Y

Citra aras keabuan kanal Y (luminansi dalam model citra warna NTSC) diperoleh menggunakan persamaan (5).

$$
Y=0.2989 * R+0.587 * G+0.114 * B
$$

dengan $R, G$, dan $B$ adalah nilai piksel pada lapis merah, hijau, dan biru.

b. Perbaikan kontras citra secara adaptif Segmentasi pembuluh darah retina merupakan proses yang cukup rumit oleh karena fakta bahwa citra retina mata seringkali berderau (noisy), mempunyai kontras yang buruk, dan pembuluh darah 
yang ada padanya sangat bervariasi (lebarnya).

Adaptive Histogram Equalization (AHE) merupakan salah satu teknik untuk meningkatkan kontras citra. Teknik ini berbeda dengan ekualisasi histogram standar dimana dalam AHE dilakukan metode adaptif dengan menghitung beberapa histogram, masing-masing bersesuaian dengan bagian citra yang berbeda, dan menggunakannya untuk redistribusi nilai pencahayaan dari citra. Namun, AHE mempunyai kecenderungan memguatkan pengaruh derau pada bagian citra yang relatif homogen. Varian AHE yang disebut CLAHE (Conrast Limited Adaptive Histogram Equalization) memperbaikinya dengan membatasi kemiringan maksimum dalam fungsi transformasinya, sehingga dapat meyelesaikan permasalahan penguatan derau yang terjadi pada AHE.

c. Median filtering

Filter median merupakan salah satu filter non linier yang paling banyak digunakan, prosesnya menggunakan topeng atau mask dengan ukuran tertentu misalnya 3x3, 5x5, dan 9x9 piksel. Pada filter median, maka nilai tengah dari nilai-nilai piksel (dalam mask) yang telah diurutkan akan dikeluarkan sebagai output.

d. Pengambangan (thresholding) dan operasi morfologi

Untuk kepentingan proses pengambangan, maka hal yang paling penting adalah menentukan nilai ambang yang paling tepat untuk citra. Setelah pengambangan dilakukan operasi morfologi berupa erosi dan dilasi untuk menghilangkan obyekobyek kecil selain pembuluh darah yang kemungkinan ikut menjadi output proses pengambangan.

e. Analisis hasil

Pada tahap analisis hasil dilakukan analisis mengenai algoritma segmentasi yang digunakan dalam usul penelitian ini. Akan dibandingkan hasil segmentasi menggunakan metode yang diusulkan dalam penelitian ini dengan hasil segmentasi manual yang dilakukan oleh pakar medis (gold standart).

\section{PEMBAHASAN}

Dalam penelitian ini digunakan 20 citra retina mata yang diakuisisi menggunakan kamera fundus. Data diperoleh dari online database DRIVE melalui website http://www.isi.uu.nl/Research/Databases/DRIVE/.

Database ini juga menyediakan hasil analisis ahli yang digunakan sebagai gold standart dalam penelitian. Gold standart dapat digunakan oleh peneliti untuk mengetahui keakuratan atau kinerja metodenya.

Gambar 1. memperlihatkan dua citra retina mata yang diperoleh dari database DRIVE.

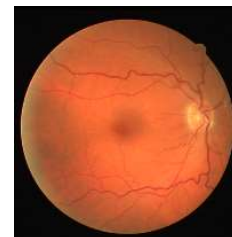

$a$

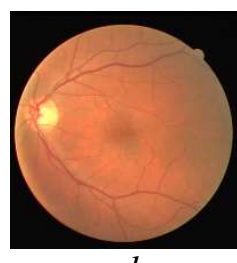

$b$
Gambar 1. Citra retina mata (a)_Citra 21_retina.tif (b) Citra 22_retina.tif

Pada Gambar 2. diperlihatkan citra retina mata yang sama dengan hanya mengambil kanal Y (luminansi) saja.

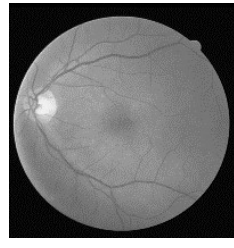

$a$

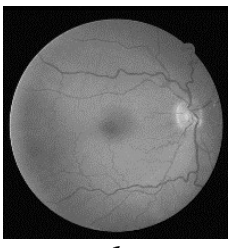

$b$
Gambar 2. Citra retina mata dari kanal $Y$

(a) Citra 21_retina.tif (b) Citra 22_retina.tif

Pada Gambar 3. diperlihatkan hasil perbaikan kontras secara adaptif dengan metode CLAHE.

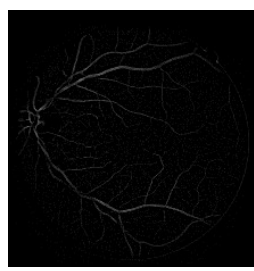

$a$

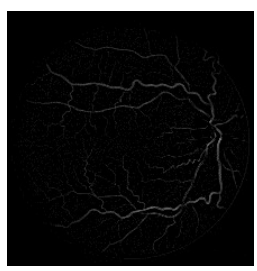

$b$
Gambar 3. Citra hasil perbaikan kontras

(a) Citra 21_retina.tif (b) Citra 22_retina.tif

Gambar 4. diperlihatkan hasil pengambangan (thresholding) untuk untuk citra yang sama. 


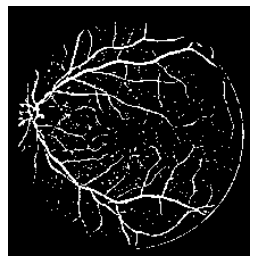

$a$

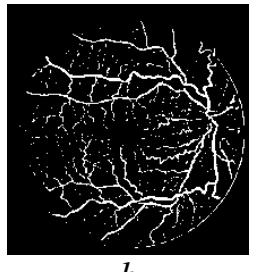

$b$
Gambar 5. diperlihatkan hasil segmentasi untuk mengekstraksi pembuluh darah pada retina mata.

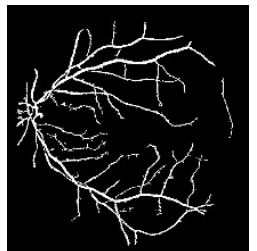

$a$

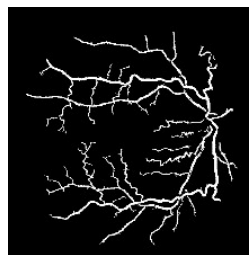

$b$
Gambar 5. Hasil segmentasi ekstraksi pembuluh darah pada retina

(a) Citra 21_retina.tif (b) Citra 22_retina.tif

Tabel 1. Tabulasi hasil ekstraksi

\begin{tabular}{|c|c|c|c|c|}
\hline No. & $\begin{array}{c}\text { Citra } \\
\text { Retina }\end{array}$ & $\begin{array}{c}\text { Hasil } \\
\text { Ekstraksi } \\
\text { Pembuluh } \\
\text { Darah }\end{array}$ & $\begin{array}{c}\text { Gold } \\
\text { Standart }\end{array}$ & $\begin{array}{c}\text { Tingkat } \\
\text { Akurasi } \\
\quad(\%)\end{array}$ \\
\hline 1. & & & & 72,37 \\
\hline 2. & & & & 61,92 \\
\hline 3. & & & & 63,72 \\
\hline 4. & & & & 62,22 \\
\hline 5. & & & & 47 \\
\hline 6. & & & & 57,29 \\
\hline 7. & & & & 62,86 \\
\hline
\end{tabular}

8.

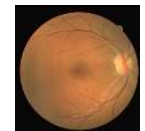

9.

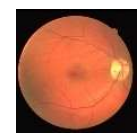

10.
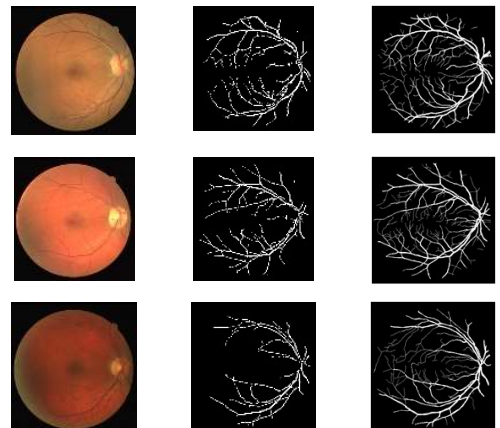

63,79
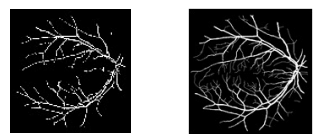

63,59
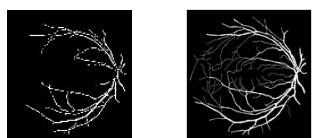

54,83
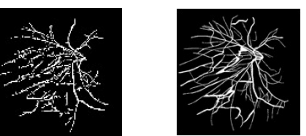

67,35
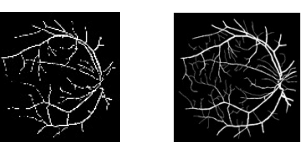

62,26
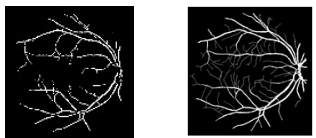

68,12
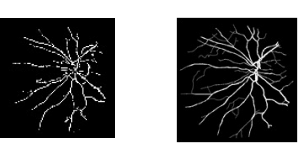

57,66
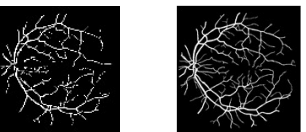

72,47
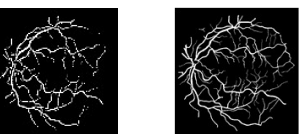

62,23

16.
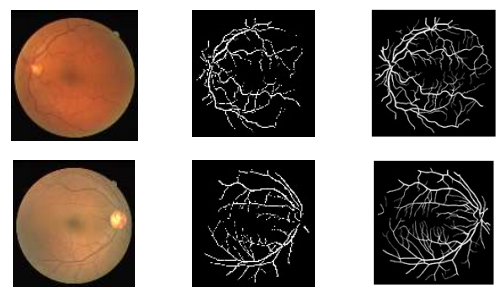

68,69
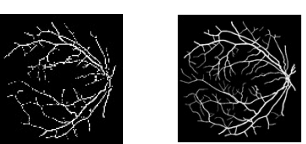

67,27

18.
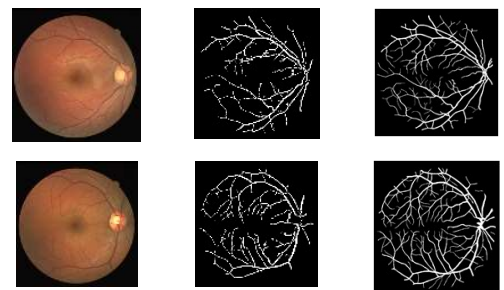

69,64
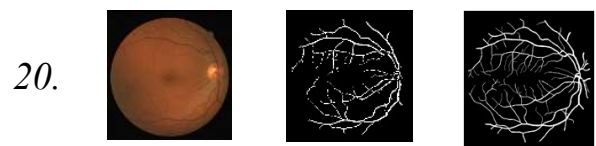

68.96

\section{Berdasarkan Tabel 1. maka} menggunakan 20 data citra retina mata, diperoleh akurasi tertinggi $72,47 \%$. Tingkat akurasi dihitung dengan membandingkan hasil ekstraksi pembuluh darah pada penelitian ini dan hasil analisis ahli sebagai gold standart. Dengan lebih memperhatikan perbandingan antara hasil ekstraksi dengan gold standartnya, maka hasil juga menunjukkan bahwa 
secara visual pembuluh darah berhasil diekstrak dengan baik, sebagian besar pembuluh darah yang tidak berhasil diekstrak merupakan pembuluh-pembuluh yang sangat halus.

\section{KESIMPULAN}

Ekstraksi pembuluh darah pada citra retina mata pada penelitian ini menggunakan data citra retina mata yang diakuisisi menggunakan kamera fundus. Citra retina mata kemudian diolah dengan mengambil citra aras keabuan kanal $Y$ atau luminansi, melakukan peningkatan kontras menggunakan metode CLAHE, kemudian melakukan segmentasi pembuluh darah yang ada pada citra mata. Penelitian menunjukkan bahwa metode berhasil melakukan ekstraksi pembuluh darah pada retina mata dengan akurasi tertinggi $72,47 \%$. Hasil juga menunjukkan bahwa secara visual pembuluh darah berhasil diekstrak dengan baik, sebagian besar pembuluh darah yang tidak berhasil diekstrak merupakan pembuluhpembuluh yang sangat halus.

\section{UCAPAN TERIMA KASIH}

Penulis mengucapkan terimakasih kepada Universitas Mercu Buana Yogyakarta yang telah membiayai penelitian ini menggunakan anggaran LPPM UMBY tahun 2016.

\section{DAFTAR PUSTAKA}

Budai, et al, 2013, Robust Vessel Segmentation in Fundus Images, International Journal of Biomedical Imaging, Article ID 154860 .

Duda, R.O., et al, Pattern Classification, Second Edition, John Wiley \& Sons, Inc.

Jain, Anil K., 1989, Fundamental of Digital Image Processing, Prentice Hall International, Inc. Singapore.
Jelinek, et al, 2007, Automated Segmentation of Retinal Blood Vessels and Identification of Proliferative Diabetic Retinopathy", Journal of The Optical Society of America, June 2007.

Kumar, et al, 2013, Automatic Detection of Vasculature from the Images of Human Retina Using CLAHE and Bitplane Decomposition, American Journal of Biomediacal Imaging, Vol 1, Article ID 20130133.

Mirzaalian, et al, 2007, Pre-processing Algorithms on Digital Mammograms, MVA2007 IAPR Conference on Machine Vision Applications, May 16-18, 2007, Tokyo, Japan.

Pavai and Selvi, 2013, Identification of Proliferative Diabetic Retinopathy Using Texture Segmentation, Journal of Computer Science, 9 (3):358-367, ISSN 1549-3636.

Saleh, et al, 2011, An Automated Blood Vessel Segmentation Algorithm Using Histogram Equalization and Automatic Threshold Selection, Journal of Digital Imaging, Vol 24, No 4, August 2011, pp 564-572.

Sergios Theodori, 2010, An Introduction to Pattern Recognition: A Matlab Approach, Elseivier Inc.

Lekamalage, et al, (2015) 'Extreme Learning Machine for Clustering', in Proceedings of ELM-2014 Volume 1 SE - 36, pp. 435-444. doi: 10.1007/978-3319-14063-6 36.

Ortiz, et al, (2013) 'LVQ-SVM based CAD tool applied to structural MRI for the diagnosis of the Alzheimer's disease', Pattern Recognition Letters, 34(14), pp. 1725-1733. doi: 10.1016/j.patrec.2013.04.014. 